\title{
Beyond Access: \\ An Analysis of the Influence of the E-Rate Program in Bridging the Digital Divide in American Schools
}

\author{
Euna Park, Hansa Sinha, and Jing Chong \\ Pennsylvania State University, University Park, PA, USA
}

eup112@psu.edu; hxs103@psu.edu; izc146@psu.edu

Executive Summary

E-Rate is a U.S. federal funding program for providing discounts for telecommunications, Internet access and internal networking costs for schools and libraries to ensure access equity across poor and rich, rural, urban and suburban areas, and highly served and underserved areas. This paper examines the impact of the E-Rate program on social equity and educational efficacy in American public schools, based upon the federal government's original purpose for investment. The investigation of these issues was based on a document analysis and interviews. As far as equity is concerned, E-Rate brought about a great improvement in providing access to information technology. However, mere access is not enough for resolving the digital divide in schools. Intrinsic problems of E-Rate, such as complex application process and inflexibility of the usage, result in disproportionate funding nationwide that actually increases the digital divide during the beginning of the program. Continuing disparities between schools regarding the quality as well as the number of connections remain. Thus, the conclusion is that E-Rate has yet to accomplish its goals in terms of closing the digital divide between rich and poor schools, rural and urban schools, and even high schools and elementary schools. As far as the effective incorporation of information technology into better teaching and learning is concerned, the study suggests that ERate can not bring efficacy to the education sector except for providing less than seamless Internet connection to schools. Connection is not necessarily related to productive technology education. Therefore, the telecom sector should align its universal service goals with the vision of the education sector and other funding agencies at private, federal, state and local levels to ensure that technology investments in schools have effective utilization.

Keywords: E-Rate, digital divide, equity, educational technology

\section{Introduction}

Material published as part of this publication, either on-line or in print, is copyrighted by the Informing Science Institute. Permission to make digital or paper copy of part or all of these works for personal or classroom use is granted without fee provided that the copies are not made or distributed for profit or commercial advantage AND that copies 1) bear this notice in full and 2) give the full citation on the first page. It is permissible to abstract these works so long as credit is given. To copy in all other cases or to republish or to post on a server or to redistribute to lists requires specific permission and payment of a fee. Contact Publisher@InformingScience.org to request redistribution permission.
E-Rate - more precisely, education rate - was enacted as part of the Telecommunications Act of 1996 and a new aspect of universal service programs in the U.S. (Bertot, 2000). The goal of E-Rate is to provide connectivity to network services through universal service principles as presented in Sec. 254 (b) of the Telecommunication Act of 1996: 
Quality services available at just, reasonable, and affordable rates, access to advanced services, access in rural and high cost areas, equitable and nondiscriminatory contributions from all telecom service providers, access to advanced telecommunications services for schools, health care, and libraries, and technology-neutral principle (not to promote the attainment of universal service through any particular telecom technologies) (http://www.fcc.gov/wcb/tapd/universal_service/).

In the past, universal service has ensured affordable telephone services in rural communities. Recognizing the growing importance of new technologies and the Internet to improve education, the U.S. Congress voted to create E-Rate and provide up to $\$ 2.25$ billion annually in discounts on telecommunications, Internet access, and internal networking to American schools and libraries. The program's expectation is to "help open new knowledge, learning and education to all Americans - rich and poor, rural and urban..." (Education and Library Networks Coalition [EdLiNC], 2003).

According to the Center for Children and Technology (2001), while technology holds great potential to help teachers and administrators overcome inequities in the classroom or the school system, it can also perpetuate and amplify existing inequities. A similar concern, the issue of digital divide in general, has been a perennial debate. Whether or not the digital divide has been bridged by increasingly wide-spread access to information technologies remains controversial (Flamm, 2004; Jung, Qiu, \& Kim, 2001).

This paper, therefore, examines the influence that the E-Rate program has had on educational equity over the past seven years (1998-2005) since the endowing of the first grants from the E-Rate program, and how effective the E-Rate program has been in teaching and learning environments. Educational equity involves engaging in proactive action to provide opportunities to all groups in society to ensure equitable educational opportunities for students' success without discrimination.

The next section reviews the literature that deals with E-Rate, its impacts, and introduces E-Rate in more detail. Research questions are derived from the literature on various issues in the E-Rate program. Research methodology includes the rationale for adopting a qualitative analysis, research design, and data collection procedures. Findings through interviews, a document analysis, and discussion appear afterwards, followed by conclusions.

\section{Literature Review and Research Questions}

E-Rate provides discounts ranging from $20 \%$ to $90 \%$ to applicants in rural and urban areas. Larger discounts go to those applicants deemed economically disadvantaged based on the percentage of students eligible to participate in the federal school lunch program. According to section 254 of the Telecommunication Act of 1996, all telecommunications carriers providing interstate telecommunications services and certain other providers of interstate telecommunications are required to contribute to the federal universal service support mechanisms as outlined in 47 U.S.C. $\S 254$ (d) (http://www.fcc.gov/learnnet/254.html).

The Schools and Libraries Corporation (SLC) was established to administer E-Rate, and in 1999 changed its name to the Schools and Libraries Division (hereinafter SLD) of the Universal Service Administrative Company (hereinafter USAC; http://www.universalservice.org/sl/). This company's guideline articulates the core features of the program as supporting "connectivity - the conduit or pipeline for communications using telecommunications services and/or the Internet." Therefore, the school or library is responsible for providing additional resources, such as end-user equipment (computers, telephones, and the like), software, professional development, and the other elements necessary to realize the objectives of connectivity. According to SLD's guidelines, the process schools and libraries adhere to apply for and receive E-Rate discounts is as follows: preparing a technology plan, opening the competitive process, seeking discounts on eligible services, confirming the receipt of services, and invoicing for services. 
Since the introduction of E-Rate in 1996, a number of political and educational issues have arisen. From the political aspect, issues concern the authority that the FCC has on imposing the funding scheme and the applications-related problems including fraud allegations. In fact, the FCC exposed many applicants nationwide for violating the program's guidelines, and some criminal prosecutions followed for fraudulent activities. Also, the role of the program in bridging the digital divide has been questioned and solved, in part, through court cases and administrative reforms (Jayakar, 2004). Jayakar summarized the controversies among many stakeholders surrounding the E-Rate program. He questioned the calls for reducing or abolishing the E-Rate program because the program has not yet achieved its stated goals of increasing Internet usage in schools, particularly disadvantaged ones. The successful achievement of connectivity nationwide, presents both a threat and an opportunity.

\begin{abstract}
It presents a threat because the very success of the E-Rate program in achieving parity in telecommunications and Internet access in schools will lead to calls for its elimination, as recent Congressional initiatives have demonstrated. It presents an opportunity because the achievement of access parity opens up the possibility of reforming the ERate program: the qualitative differences evident in the data suggest that programs such as E-Rate still have a mission to fulfill and that termination may be a less desirable option at present than continuation with reform (p. 40).
\end{abstract}

As indicated in this argument, now is the critical time to reconsider the intentions of the funding program and reform of the program based upon an evaluation of implementation. However, unfortunately, the evaluation of performance, as well as administration/management issues, have been recognized even by the government and some scholars as critical drawbacks of this program (United States Government Accountability Office [US-GAO], 2005a, 2005b). For example, the most recent government report about E-Rate reveals that "the FCC has not developed meaningful performance goals and measures for assessing and managing the program. As a result, there is no way to tell whether the program has resulted in the cost-effective deployment and use of advanced telecommunications services for schools and libraries" (US-GAO, 2005b, p.2). Indeed, as Hudson (2004) indicated some disparities exist in the take-up rate of E-Rate subsidies between affluent states and states with significantly disadvantaged and/or rural populations. The managerial problems may explain possible reasons for the unfair allocation of the E-Rate funds. The inequitable distribution provides evidence for a suitable revision of E-Rate implementation and government support mechanism.

One of the assumptions of the E-Rate program, upon conception by Congress, was that computers and Internet access can have a beneficial effect on educational quality and equality (Jayakar, 2004). Educational quality refers to better performance by students who have assistance from integration of information technology into curriculum. Even though many concerns and debates about the E-Rate program remain (Cuban, 2001; Jayakar, 2004; Shuler, 1999), the most important and practical question at present would be whether the program has achieved even the original Congressional goals of the policy for universal service: providing quality services at just, reasonable, and affordable rates, and advancing their availability to disadvantaged groups such as rural and poor people. Given that this program began with the purpose of enhancing the concept of universal service, has the program provided an advanced telecommunication network access in an equitable way? How has the E-Rate program affected the enhancement of equity in elementary and secondary schools? Has it contributed to closing the digital gap between schools in rural, urban and suburban areas, and between rich and poor residential areas?

On the other hand, many researchers have raised questions about the effectiveness of computers and Internet access in the classroom including pragmatic questions about how to integrate advanced technologies into curricula (Bertot, 2000; Hudson, 2004; Jayakar, 2004). These researchers' agreement is that providing Internet access and networking service does not automatically 
increase the quality of education. In his investigations of computer and Internet use in schools in California's Silicon Valley, Larry Cuban found that "most students' uses of computers were peripheral to their primary instructional tasks" (Cuban, 2001). Others, too, have confirmed Cuban's observations (Goolsbee \& Guryan, 2002; Guthrie, 2003). After significant numbers of observations, Guthrie (2003) concluded that, despite most public schools having Internet connection, few classrooms took advantage of the electronic highway. Also, in an empirical study that evaluated the effect the E-Rate subsidy had on Internet investment in California's public schools, Goolsbee and Guryan (2002) stated, "There is very little evidence that the program has had any measurable outcome on student achievement...measured by test scores in a variety of subjects" (p.18). On the other hand, digital divide researchers have recognized that without proper support in the school and home environment, computers in the schools probably do not provide much of an educational benefit (Noll, Older-Aguilar, Rosston \& Ross, 2000). Even telecom scholars discovered that the E-Rate program does not appear to play a statistically significant role in encouraging broadband use (Flamm, 2004). Thus, a question about the efficacy of the E-Rate program in terms of the improvement in the quality of teaching and learning is another inquiry dimension of the program in this paper. Thus, the research questions are:

1) What impact does the E-Rate program have on closing the digital divide across the country? (e.g., between rural and urban schools, rich and poor residential areas, and elementary and secondary schools)

2) How have telecommunications and information technology (e.g., Internet connection), established by the E-Rate program, been integrated into the teaching and learning processes?

\section{Methodology}

\section{Rationale for Conducting a Qualitative Investigation}

Response to the research questions employs a qualitative approach. This occurs by analyzing secondary documents, and at the same time, this document analysis has the complement of interviews with experts who have followed the development and controversies surrounding the implementation of the E-Rate program. One included observation at a school provides valuable suggestions for the integration of technology within the school system as combined with other methods.

The belief is that qualitative research is the most advantageous for investigating this topic. Evidently the E-Rate program has narrowed the access gap between rich and poor schools, only if regarding equity as access (Dickard, 2002; Hudson, 2004). A number of surveys and observations with respect to the effect of E-Rate have already occurred. They have provided detailed statistical data on, for example, the number of computers, the ratio of computers to students, the amounts of discounts, etc. (Macias, 2001). However, the question remaining is the effect of E-Rate beyond access, which cannot be explained simply by statistical numbers. A more comprehensive understanding of its practical context in the educational environment is necessary.

First of all, the assumption is that improved technological access is far from resolving the educational inequity influenced by multiple contextual factors. Therefore, to simply look at the statistical data does not take into account the complicated contexts and provide proper answers to the research questions, which intend to examine qualitative aspects of educational equity beyond the number of students with access.

Second, the integration of technology in the school system is still in its infancy. Undoubtedly, the E-Rate program has been successful in bringing information and communication technology to schools, but much of the technologies' educational value has yet to be proved. Teachers have to 
learn technology themselves and then conceive of the best ways to use it. Different schools and teachers are using computer technology in different ways. As such, a tremendous degree of variation involves how technology gains acceptance and integration within the school.

Third, this research's epistemology is interpretive. The belief is that the effect of implementation of technology depends on people's subjective awareness. Teachers react to the new phenomenon according to their own skill levels, and socio-cultural backgrounds. Students, too, react to technology according to their skill levels which depend on availability of computers in their homes, as well as other socio-economic and cultural factors. Daniel Callison's (2004) example best illustrates the qualitative nature of this subject of inquiry. He found that the most challenging digital divide is a generational one. In the past two years, the gap between teen and teacher has widened. And the gap is growing, not just between the tech-savvy teen and the tech-shy teacher over forty, but between tech-savvy teens and young teachers, even pre-service teachers.

\section{Research Design}

The literature review process revealed that case studies, observations and round table discussion reports from various organizations and research project groups involving the E-Rate program offer invaluable resources for investigating the research questions. Although interviews in schools are possible, the research decision is to concentrate on a document analysis using secondary data because: (1) Each school has its own situation which varies by school. Even though individual variations are important for investigating E-Rate impacts on teaching and learning processes, the sheer number of public schools has led to adopting the more practical choice of a document analysis and expert interviews. (2) Most of the secondary data obtained arises from nationwide surveys, and thus, draws much more complete picture. A document analysis using secondary resources would be sufficient to answer to the questions which query the impact of E-Rate funds.

The reports obtained come from the organizations listed below with their own mission statements. They may be accessed via the official FCC E-Rate site (http://www.fcc.gov/learnnet/), and associated resources are listed below.

The Universal Service Administrative Company (USAC): This organization administers the Universal Service Fund (USF) and provides communities across the country with affordable telecommunication services. "The SLD of USAC provides discounts to assist most schools and libraries in the U.S. to obtain affordable telecommunications and Internet access. Its oversight includes (i) determining how USAC will project demand for schools' and libraries' programs, (ii) developing applications as needed for programs, (iii) administering the application process, (iv) determining discount levels, (v) performing outreach and education functions, and (vi) developing and implementing other distinctive program functions" (http://www.sl.universalservice.org/). USAC posts, online, the E-Rate program overview and annual reports which are sources for this research.

Benton Foundation: The mission of the Benton Foundation is to articulate a public interest vision for the digital age and to demonstrate the value of communications for solving social problems. The Benton Foundation believes that educational technology holds great promise for improving teaching and learning. They advocated, successfully, for the creation of E-Rate and have tracked the development of the federal program. They continue to highlight what is at stake and areas of policy improvement in the education technologies arena. In particular, two resources were identified for the analysis, Dickard $(2002,2003)$.

Consortium on School Networking (CoSN): From its earliest days, CoSN has been a guide for educators interested in effective use of information technology in the classroom and has been the national voice on use of the Internet and information technologies to improve K-12 learning. 
Their membership includes key technology leaders from school districts and states, as well as leading corporate partners. CoSN formed the original coalition that convinced Congress to enact E-Rate; the most critical education technology funding mechanism in the U.S. CoSN continues to work to ensure the integrity of this $\$ 2.25$ billion program for schools and libraries. CoSN conducted a nationwide survey of key decision makers in K-12 public schools and published the results in The Consortium for School Networking (2004).

The Education and Library Networks Coalition (EdLiNC): The Education and Libraries Networks Coalition, formed in 1995, represents the viewpoint of public and private schools and libraries in the FCC proceedings that deal with the implementation of the Telecommunications Act of 1996. The Coalition seeks to expand the use of educational technologies in schools and libraries by making sure that these entities receive the affordable rates guaranteed to them in the Universal Service Provisions of the Telecommunications Act. The Coalition also published an E-Rate report (Education and Library Networks Coalition, 2003).

Other documents used as sources for this analysis were Goolsbee and Guryan (2002), Macias (2001), and Staihr and Sheaff (2001). These may be a little out of date, but other succeeding studies were not identified when this study was conducted. Therefore, interviews with experts provide a complement for the analysis.

This study's interview data comes from six information technology, education technology, and telecommunications faculty members from a research university in the East. Interviewee A is in the College of Communications. He is deeply involved in the subject and has most recently authored a paper on E-Rate. His perspective is more from the administrative, political and economic aspects of E-Rate which involves the telecommunication sector. Interviewee B is, again, from the same college. His research interests focus on the social and policy consequences of the production and consumption of information. A Latino from South Texas, he maintains a special interest in policy as it relates to ethnic minorities, and he is author of the telecommunications policy agenda for the Congressional Hispanic Caucus. His main focus for research is on universal service and digital divide issues.

Interviewees $\mathrm{C}$ and $\mathrm{D}$ chosen from the School of Information Science and Technology, also hold positions in the College of Education. Interviewee $\mathrm{C}$ is field-oriented and an excellent observer of technology before and after the introduction of E-Rate. He emphasizes the influence of sociocontextual factors on the introduction of Information technologies. Interviewee D's expertise is in the use of computation to support and augment human performance and learning. He identifies the limits to technology in education. He does not believe that technology has revolutionized education.

The last two interviewees had significant practical experience. Interviewee E works with practitioners in education and has a major voice and leadership role in promoting the effective use of information technology in educating school children. Interviewee $\mathrm{F}$ is active in studying the impact and value of online learning in a variety of areas, such as, student outcomes, faculty outcomes, institutional impact and change management, and quality control. The goal of the organization she heads is to provide such knowledge to distance education practitioners and decisionmakers in a variety of educational contexts. This study's document analysis has the complement of interviews and observation. Triangulation in the research design increases the credibility of the results.

\section{Data Collection Procedure}

The co-authors of this paper bring individual perspectives to interpretation of the data. One researcher is a PhD student in the College of Communications with an area of interest in telecom- 
munications policy. The other two researchers are $\mathrm{PhD}$ students in the College of Information Science and Technology (IST) with emphases on education and digital divide respectively.

Configuration of the questions for the interviews intends to discover the impact of the E-Rate program on the digital divide particularly in terms of its effectiveness in the educational sector. Each researcher conceived of some questions according to individual interest in the subject. Researcher A developed questions about the administration of E-Rate, the complexity of the application process and the controversies surrounding its introduction. Researcher B's questions concern the impact of the program in bridging the digital divide, and Researcher $\mathrm{C}$ questions the effectiveness of internet access in teaching and learning. Several open-ended questions arose to capture new ideas and categories during the interview process, and subsequently, help refined the final questions for the impending interviews. The final questions appear in the Appendix. From the analysis and interpretation of the data, some new categories emerged later incorporated as new questions for the next interview. Table 1 shows data categories finally utilized for analysis.

Table 1. Data Categories for Analysis

\begin{tabular}{|c|c|c|}
\hline & Categories & The Specified Points \\
\hline $\begin{array}{l}\text { Efficacy } \\
\text { Aspect }\end{array}$ & $\begin{array}{l}\text { Positive impact of Information Technology on } \\
\text { teaching and learning } \\
\text { Problems with actual use of technology }\end{array}$ & 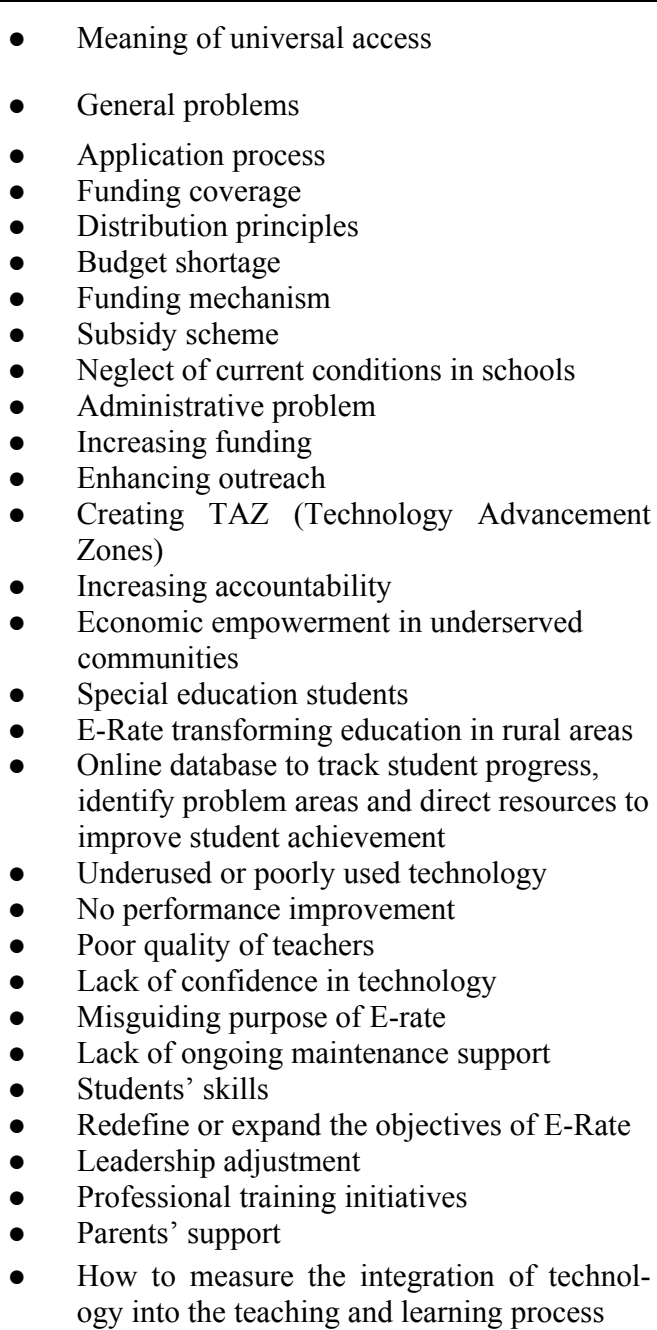 \\
\hline
\end{tabular}


One researcher had the opportunity to attend the monthly Principal's meeting with the parents at a local school. While there, she asked some questions about the state of information technology in the school. The meeting occurred in the school library where she observed a class being conducted using information technology. This was completely ad hoc. She also asked a schoolgirl about computer use in the classroom and how often students went to the computer lab. Later, during interviews and through document analysis, this researcher was able to verify her own interpretation of the observation and meeting.

Once collected from interviews and documents, data were categorized according to each interview question. The data, color coded according to the data source, allowed interpretation in relation to the characteristics of the organization that produced the document and the orientation of the interviewee.

\section{Findings}

\section{The Impact of E-Rate on the Digital Divide in Education}

\section{Current conditions}

Controversy exists about the positive impact of E-Rate on the digital divide in schools. If digital divide just concerns access to technology, then it can be said that the E-Rate has helped to significantly collapse the gap, if not completely bridge it, which can be seen from the statistics of the increasing number of connected schools and students over the years. "In the early 1990s, very few schools had more than one computer, but in the late 1990s, most schools had computers and connectivity to internet" (Interviewee B). Due to technology budget cuts recently, the importance of E-Rate in each school district has been increasing.

However, since the Internet's diffusion to every sector of society, many other similar programs promote Internet use in education, such as state-funded initiatives, Technology Literacy Challenge Fund, and State Education Technology Plan. Thus, no assurance exists that the narrowing of the digital divide is solely due to E-Rate, although it has had the most impact as shown in the survey from the National School Boards Foundation (2002). The survey found that $71 \%$ of the respondents identified E-Rate as the most significant outside initiative.

Despite the success, problems remain. Firstly, some schools lag in applying for E-Rate funding due to lack of resources to handle the highly technical, complicated, and laborious application process that is decentralized (e.g., time and resources to create technology plans, training resources for technology and curriculum development, and financial resources to create technology programs as well as maintenance and development). "It is so complicated because to get it funded we had to make it so intricate that many of the schools who needed it most had no way of applying because there was no grant writer or residual technical person to write the grants" (Bracey, 2004).

Rural schools lacked the expertise to develop proposals, and the FCC does not help in this area (Dickard, 2003). The role of SLD is to administer the program rather than to promote and help applicants apply. Furthermore, SLD simply cannot appropriate the funding for the promotion purpose, so that E-Rate has not been popularized enough. As a result, E-Rate can be unintentionally deepening the digital divide because wealthy schools are more likely to have the capacity to apply for funds than are poor schools. Besides, the length and complexity of the application process have caused schools to depend on consulting firms or telecom companies, which are not supposed to be involved in the process due to the potential for administrative fraud issues. 
Second, although the digital divide, in terms of basic access to the Internet, is not so serious an issue now, other forms of the gap remain. A divide still exists in broadband access - "A question of broadband access is not fully resolved" (Interviewee B). Second, a divide remains between high schools and elementary schools because of different degrees of sensitivity to access price, with high schools usually more willing to pay whatever the price to increase Internet access. Third, a racial divide remains. Schools with large populations of black and Hispanic students are more sensitive to access price due to constrained budgets.

\section{Reasons for the current problems of equity}

There are multiple reasons for the current problems. First, huge gaps exist between demand and supply for the funds (Dickard, 2002; EdLiNC, 2003). In 2002, the FCC received $\$ 5.2$ billion in ERate requests - more than twice the $\$ 2.25$ billion available for distribution. Thus, the FCC gave priority to funding internal network connections to districts that did not receive such funding in previous years. The E-Rate budget is threatened by demand exceeding the supply (Schools and Libraries Division [SLD], 2005). "Funding requirements have gone up; revenues of telecom industry have gone down. It's unsustainable" (Interviewee A).

Second, disproportional funding and management problems on-site have been obstacles for expanding the benefits in an equitable way. The school districts have responsibility for applying for and distribute E-Rate funds to the schools within their jurisdictions (Goolsbee \& Guryan, 2002). Since schools within the same district have different discount rates, the district does not inform the schools whether the funds are distributed evenly or by different percentages. This lack of communication and organization at the district level jeopardizes accountability in the E-Rate program. Therefore, a federal funding mechanism would better supervise management because the government can collect great amounts of money more easily and distribute evenly on the basis of districts' needs.

\section{Measures to improve equity}

The successful experience of Alaska in acquiring the highest per capita E-Rate funding, in spite of its being the most rural state and having a large minority population, identified several factors that contributed to this success (Hudson, 2004). These factors can be usefully employed at both national and local levels. First is commitment to using telecommunications for development and absorbing the Internet into schools. Second, an E-Rate coordinator, assigned from librarians, assists schools prepare applications and tackle problems in this intimidating process. This librarian's responsibility is to give advice, explain requirements, and provide assistance in completing forms and tracking progress. A reasonable assumption is that assistance from resource persons can be valuable for ensuring success in obtaining funds. Third, telecommunications and Internet access carriers can help schools obtain funding by offering a package of services, including connectivity via leased line. Local telephone cooperatives can also partner with schools and libraries to obtain discounted Internet access (Hudson, 2004).

Other measures include: (1) urging the Congress to lift the $\$ 2.25$ billion annual limit on E-Rate funding and expand the coverage of E-Rate to computer infrastructures; (2) Increasing outreach efforts to schools which need funding most and ensuring their awareness of the opportunities that the E-Rate program offers; (3) Creating TAZ (Technology Advancement Zones) by identifying the poorest schools and communities where schools can receive federal, state and private funding in the forms of computer, teacher training, infrastructure, software, technical support and grants; (4) Increasing accountability by creating an inventory of available funding sources and conducting an audit of those who receive E-Rate funds and those high-tech corporations who invest in schools. 


\section{The Impact of E-Rate on Teaching and Learning}

This section answers the question of whether or not E-Rate can contribute to the integration of technology into the teaching and learning process, and from a practical perspective, how telecommunications and information technology, initiated by the E-Rate program, have improved the education. Indeed, the digital divide has been increasingly perceived as more than access. The actual use of the technology in teaching and learning by schools is most important. However, as always acknowledged, the availability of technology does not necessarily lead to the actual use of the technology. One interviewee mentioned, "You can provide access to five copies of Constitution to five different people, but you can't force them to read it."

\section{Current conditions}

E-Rate is an important tool for economic empowerment in underserved communities (EdLiNC, 2003). For example, in Fort Benton, Montana, the public school business teachers use online business development kits to teach students to run small businesses in the area. In remote Bethel, Alaska, teachers go online to take courses in a wide range of subjects from special education to social work. E-Rate also has expanded its benefits to special education students: at the Rochester School for the Deaf in New York, deaf students and faculty are now able to use e-mail to communicate with each other and the hearing world. At the Wisconsin School for the Deaf, students can sign on to five online classes per day in American Sign Language. "At risk" students, who have educational, behavioral or special needs, also benefit from technology made possible through E-Rate funding. For example, the so called "Jason project" in the Good Will Hinckley School in Maine connects students with personal and educational challenges with scientists to examine biological and geological data. Also, the technology access has improved communications between students' guardians and caseworkers.

E-Rate is transforming education in rural area. Distance learning and video conferencing incorporated into the regular curriculum of these schools, resolves a chronic problem of teacher shortage and provides students an outlet to channel their communications with the outside world. Thus, rural schools say that without E-Rate funding, the district would be educationally hamstrung.

E-Rate technology helps improve student achievement and complies with the No Child Left Behind Act (NCLB) (White House, 2003). Many school districts develop an online database to track student progress, identify problem areas, and direct resources to improve student achievement. For example, in Washington's Bridgeport School District, administrators employ online testing, diagnosis, and prescription. EdLiNC (2003) argued that the Internet is "not just a plaything" (p.11) but improves test scores of students in real terms.

However, having technology does not necessarily translate to effective use (Interviewee C). Startling gaps exist between the promise and reality of technology use in schools. In some schools, "they simply put technology on the back burner" (EdLiNC, 2003) and computers are only up and running $80 \%$ of the time. It also happens that kids are locked out from a computer room due to safety issues. For the protection of facilities, children are often not allowed to access to the computer lab other than a designated class time (Interviewee C). Sometimes, computers are a reward rather than a pedagogical device (Cuban, 2001), and the Internet remains primarily a research tool, not a forum for interactive teaching, learning, communicating or collaborating. "The underuse of computers contrasts with the fact that students sometimes overuse computers in front of them in class for such non-curricular purposes as instant messaging, emailing and gaming" (Interviewee D).

Besides, schools have yet to fully integrate technology with classroom teaching and learning. Computer labs and media centers, instead of classrooms, are the most likely points of Internet access for students in their schools. A huge mismatch occurs between classroom access and stu- 
dent use of the Internet (Consortium for School Networking [CoSN], 2004). Classrooms need to be connected, not just schools (Dickard, 2003). This is especially problematic for the poorest school districts. Hardly any evidence exists for any measurable effect on students' performance by investing in the Internet (Goolsbee \& Guryan, 2002). Interviewee D also identified an easily neglected problem: the availability of computers to teachers, the leading characters in the classroom education. Interviewee $\mathrm{F}$ felt that rural schools continue to encounter the problems of slow connections which are a major hindrance to distance education through online learning.

\section{Reasons for current problems in the efficacy of E-Rate}

On the part of teachers and school administrators, many teachers do not have the necessary skills to integrate technology into their instruction due to a lack of proper training (Macias, 2001). Interviewee $\mathrm{F}$ observed that teachers vary in their readiness for technology integration: they did not receive training according to their needs. Half of school leaders cite lack of training as the most serious barrier to more effective data-driven decision-making. This is a particularly serious problem in the poorest school districts. Furthermore, surveyed teachers "don't really believe that technology is the answer to their problems" (Honey, 2002, p.23). The teachers generally do not view technology as a means to expand curricula beyond basic skills instruction, but rather technology is simply another means to accomplish basic work (Honey, 2002). Comments such as "building a multi-million dollar computer network may be easier than helping schools learn to use that technology well," and "Books are just more important" represent the prevailing sentiments of the integration problem (Dickard, 2002, p.18). For example, one teacher asked, "Why should I spend time teaching my kids to do something on the computer that they could do just as well the old way with poster board?"

On the part of students, although the novelty can motivate students in the short term, access to technology itself will in no way be sufficient to sustained learning, over time. Because of a lack of computer skills, students are not using the Internet productively. The justification for technology in the classroom lies not in simply teaching students how to use technology, but in teaching them how to use it well (Gersick, Kim, Keane, Friedman, \& Culp, 2002). The challenge facing teachers is "not how to teach content with technology, but how to identify and develop the unique skills associated with new media and technologies" (interviewee F).

On the part of the E-Rate program itself, it was not meant as an educational program in the first place; instead it was meant as a telecom access program. Its aim is just to provide the ready connection, and the schools have the responsibility for attending to how to use it, having nothing to do with educational efficiency. "Efficacy is an important question, but not an E-Rate question" (Interviewee B). Moreover, "Companies should not be held responsible for quality of education and educators should not be held responsible for the efficiency of connectivity" (Interviewee B). As a result, ongoing, adequate technology support is one of the greatest challenges for school districts (Interviewee C). If a teacher makes the effort to adapt a lesson plan to the online environment, only to find that the network is "down" that day, why would she not return to relying on more traditional approaches (Dickard, 2003)? Furthermore, lack of capable software can also limit what teachers can do with the high-speed network. "It's a great leash, but there's no dog" (in Kansas City case cited in EdLiNC, 2003, p.20).

Second, E-Rate only covers network connection without consideration of infrastructure and sustainability. "Second goal is maintaining connectivity. Everything that happens inside school does not get covered by E-Rate." (Interviewee B) In the early years of this program, many schools had to spend millions in local funds to upgrade electrical systems that previously could not support computers, printers, and other peripherals. However, since E-Rate does not support electrical upgrades, these schools had to spend their local budget to receive E-Rate. Powerful networks can stall when classrooms lack sufficient hardware. Consequently, this limitation of the support has 
been criticized by many commentators and academics who argue for expanding the list of eligible products, services, and vendors (Dickard, 2002; Jayakar, 2004). Therefore, maintaining connectivity should be the next concern of education technology investment. "Once government built a road, government should commit itself to maintain the road." Obviously, "The U.S. invests money in wrong places" because the payback from investing in education is much more than in weapons. "Many observers liken the need for a world class, high-quality educational system to a national security issue" (CEO Forum on Education and Technology, 2001). Besides, the nonstandardization of technology adds to the cost of maintenance.

Third, the E-Rate program has been practiced with little consideration for human factors. Computers, as mere technologies, have their innate restrictions and may not fit very well for direct application into education without any previous customization. Builders, often engineers, have little knowledge of education, although they might think they have (Interviewee D). What should also be taken into account is how social and cultural elements might influence technology use in classrooms.

\section{Measures to improve efficacy of the E-Rate program}

Only if a link exists between E-Rate and the educational objective does real effectiveness exist in the incorporation of technology into education. Interviewee D firmly believes that, shown in the following diagram (Figure 1), access, even seamless access, is far from enough. It has to be combined with effective leadership, tech-ready teachers, and effective practice in order to achieve the improvement in student learning. Large school districts should create a senior, full-time position of chief technology officer. Smaller school districts should explore the possibility of pooling their resources and sharing the services of a chief technology officer (CoSN, 2004). Every school district in the country should schedule routine technology workshops to continue the learning process for educators. Professional development should be a major part of technology budgets (up to $30 \%$ ). Federal funding should be increased for enhancing training through technology programs and preparing tomorrow's teachers to use technology (CoSN, 2004).

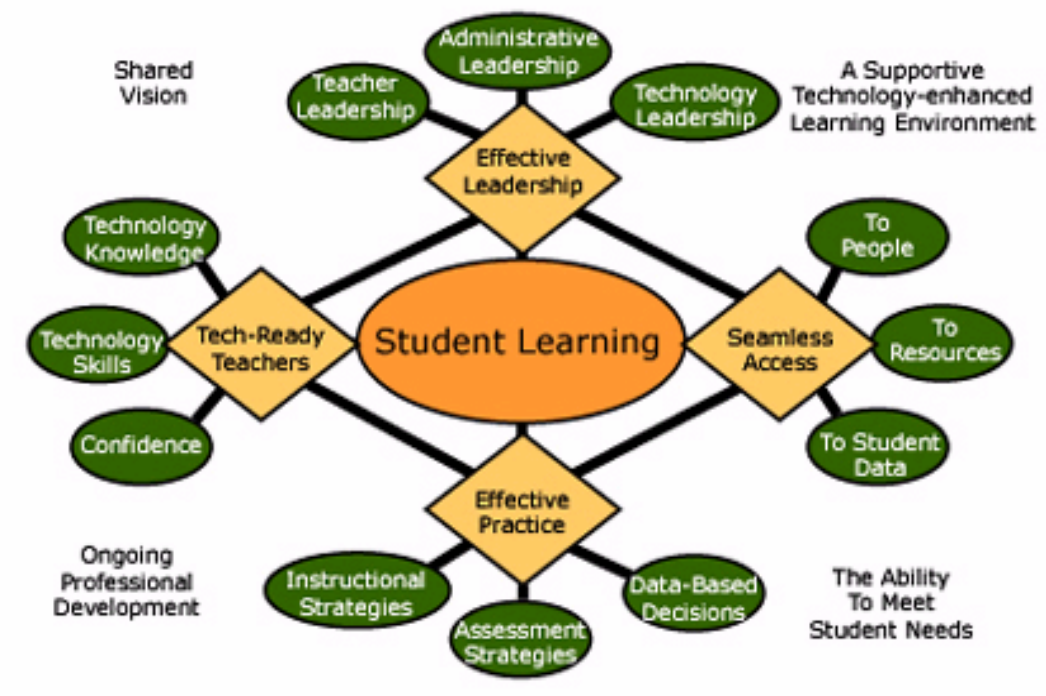

Figure 1. Pennsylvania: Using technology to enhance student learning Source: http://www.ed.psu.edu/EETT/EETT1024x768Kyle/update/EETT1024x768.htm 


\section{Discussion}

The research questions arose from the inquiry into whether or not the E-Rate program has really achieved its mandated goals: equity and efficacy. The inquiry is critical at the moment fraud allegations surrounding the application process for E-Rate have cast doubts on E-Rate and caused controversy over even the duration of the program (Jayakar, 2004). In the fall of 2004, when the FCC suddenly stopped apportioning the E-Rate funds upon the recognition of fraud and misappropriation of funds, many schools and libraries became anxious about the sustainability of their network infrastructures (Shiver, 2003; Whelan, 2004). No schools or libraries had been left without Internet service, but the cash-flow problem caused hardships for E-Rate recipients who relied on the federal program for Internet and telecommunications service. In this background, examining whether or not E-Rate has even fulfilled its purpose of bringing more equity in society resulted in invaluable insights for understanding the advisability of sustaining the program despite much criticism surrounding it.

\section{Problems of the E-Rate funding scheme}

The findings, overall, agree with other commentators' and scholars' observations (Cuban, 2001; Dickard, 2002; Hudson, 2004; Jayakar, 2004; Thierer, Crews, \& Pearson, 2002) in that, even though E-Rate helped the exponential growth of connectivity, it still has quite a way to go. Although this tremendous investment by the federal government has provided more access to advanced technologies in schools, it appears to have failed to genuinely close the digital divide in the U.S. In other words, a great disparity between the goals of E-Rate and its implementation was discovered. Markedly, Internet connected schools and student to Internet connected computer ratios have improved. However, as indicated in the earlier analysis, some schools in more isolated and poorer areas lag in applying for E-Rate funding and maintaining the advanced technologies later on. Deficiencies of resources, necessitated by the highly technical and laborious application process, are still problematic in these schools. Time and human resources to create technology plans and applications, training resources for technology and curriculum development, and financial resources to furnish the necessary hardware and software to obtain E-Rate funding as well as to maintain the networks are still burdensome to these schools.

Reports from education-related organizations uniformly argue that disproportional funding and management problems in the schools have been obstacles for expanding the benefits in an equitable way. Schools districts have responsibility for applying for and distributing E-Rate funds to the schools within their jurisdictions. Since schools within the same district have different discount rates, the district commonly does not inform the schools whether the funds are distributed evenly or by different percentages. This lack of communication and organization at the district level jeopardizes the accountability of the E-Rate program.

This funding scheme, compounded with the length and complexity of the application process, results in some "bureaucratic hassles" (Trotter, 2000). Especially, the administrative fraud issue has resulted from these intrinsic problems of E-Rate. For the application, many schools depend on consulting firms or telecom companies which should not be involved in the process. As indicated earlier, the application process for E-Rate funds consists of complicated multiple stages. Some of these stages are resource and time-intensive and require expertise and technical knowledge, which are usually rare in poorer schools. Despite a constant effort SLD has made for clarification, the ambiguities of E-Rate applications and procedures remain currently criticized (Murray, 2005).

Dickard (2002) highlighted one survey report, "Connecting California's Children: Is the E-Rate Enough" to identify the drawback of E-Rate. According to this report, many Californian underserved schools did not feel they could negotiate the laborious and technical process. They simply did not have the time or staff with expertise to deal with this. The report even revealed that "A 
$43 \%$ of the disadvantaged schools did not even know about E-Rate" (p.16). When considering this survey conducted in 2001, the presumption is that these schools must have received the funds in the end. However, from this example, one question arises: Why government did not pay attention to promoting the program at the very beginning of E-Rate execution? The role of SLD is to administer the program rather than to promote and help applicants apply. Furthermore, SLD simply cannot appropriate the funding for the promotion (or education) purpose. As a result, E-Rate can be deepening the digital divide in some ways because wealthy schools are more likely to have the capacity to apply for and maintain the funds than poor schools.

Surely, the E-Rate program affects the enhancement of equity in elementary and secondary schools. High schools usually are more willing to pay whatever price to increase Internet access, while elementary schools will only invest in highly-subsidized technologies. Thus, E-Rate has contributed to more connectivity to elementary schools. In another way, this means that without a subsidy like E-Rate, connectivity in elementary schools would most likely disappear. Also, rural schools suffer from isolation, under-funding, staff shortage, and limited resources. Since E-Rate's only concern is connectivity, rural schools still have to obtain funds from other sources for maintaining Internet access. The equity between disabled students and those who are not, and between girls and boys, has never been considered in the E-Rate subsidy scheme. Thus, although the connectivity provided more opportunities to disabled students, as seen in EdLiNC's case studies, uncertainty remains whether or not E-Rate could ever close the gap among these students.

\section{Refining the definition of connectivity}

What is more, neither access nor universal service has clear a definition in the telecom sector. Does access mean one computer per student or a few computers per classroom? Or does it mean just a computer lab in one school? Also, even connectivity lacks clear definition. Does it mean dial-up Internet connection or T-1 line broadband connection? These ambiguities in the definitions make E-Rate appear to be a catchphrase and end as a mere gesture rather than an exceptional federal effort to resolve the educational digital divide.

One noticeable fact is that significant numbers of students in poorer areas can only depend on public access; for example, while $95 \%$ of the highest income households have home access, only $33 \%$ of the lowest income households have Internet at home (Dickard, 2003). This does not mean that E-Rate supports home access. However, when schools have not exploited technology in classrooms to its full potential (CoSN, 2004) and allow student use technologies at special places, such as computer labs or media centers during school operating hours, how do students with no access to the Internet after school find a help with their homework? In such a situation, justifying that the provision of access to the Internet at schools will prepare students for new digital information world becomes difficult. This simply implies that schools have to reconsider their technology operations and try to provide students with technological needs, even after school.

\section{Tuning up different perceptions}

Overall, this study's findings about E-Rate suggest a huge gap in terms of the perceptions of both the telecom sector and the educational sector. In the telecom sector, E-Rate is perceived as a part of universal service and a step-child born from a political deal between the government and telecom companies rather than an educational initiative. This difference in perception is clearly apparent in the interviews with professors in telecom and in education. Two interviewees in the telecom department reemphasized that the purpose of the program was to provide connectivity, not educational efficacy, as opposed to the expectations of the educational sectors. Seemingly growing contributions from telecom companies to the funds, as well as complaints about the burden (even called hidden tax on telecom companies), have caused extensive debates on whether or not to maintain this program (Jayakar, 2004). This perceptional difference is inherently inevitable 
because E-Rate was created from the Universal Service Fund; it cannot expand beyond this USF scheme. For example, the costs incurred by states, schools, or libraries to build or purchase wide area networks (WANs) to provide telecommunication would not be eligible for universal service discounts because such networks do not meet the criteria of services eligible for support (Federal Communications Commission [FCC], 2004).

Unfortunately, due to the educational technology budget cuts at the state and local levels lately, the importance of the federal funding program in school districts has increased. Thus, E-Rate can influence the sustainability of school networks and technology plans more than ever before: "If the E-Rate were taken away, the Internet will be gone from schools" (Interviewee B). At the moment, consolidating the separated efforts for funding schools' educational technologies might be considered, as the Bush administration suggested. The Bush administration proposed a set of school technology initiatives that included E-Rate reform (White House, 2003, cited in Jayakar, 2004, p.46). This proposal combines E-Rate and other school technology funding plans into a consolidated grant program that will allocate money to states and school districts based on a formula, with a preference given to high-need schools, rural schools, and schools serving poorer students. Schools would no longer have to apply for funds, but would be awarded technology funds as a block grant according to the formula that also accounts for need (Jayakar, 2004). However, this paper argues that without a commitment to education, the original goal of the subsidy for telecom connectivity and realization of equity would be never achieved.

\section{Political Suggestions}

Based on the findings, some political suggestions are appropriate: First, the FCC should be aware of the fact that connectivity only does not guarantee better equity and better education. The ERate scheme leaves much room for revision, such as simplification of the application processes and balancing supply and demand. Second, E-Rate is at a crossroad intersecting a part of telecom policy and educational concern. Thus, to examine a one-dimensional aspect is insufficient for identifying implications of this program. The collaboration with educational sectors while implementing E-Rate is advantageous. In particular, the SLD needs to seek out areas that are most needy. Then the SLD and school districts together must make sure that schools are following technology plans and educational goals which should address teacher training, technology leadership training, and encouraging effective practice in the classrooms. "Educational objectives cannot be achieved unless the educational system is aligned to support them. State, districts and schools must ensure that technology use aligns with standards, educational objectives, curriculum and assessment. This would be an iterative and evolving process" (CEO Forum, 2001).

To evaluate the success of E-Rate, asking about numbers related to connectivity is insufficient without assessing the benefits realized in the targeted places. Although, after a long debate on the abolition of E-Rate, E-Rate might be eliminated in telecom eventually, the objectives of E-Rate, improving equity and efficacy in education should be consistently pursued.

\section{Limitations}

To the extent of the survey, no previous study combines perspectives from both the telecom sector and the education sector. This paper, therefore, contributes to unifying the viewpoints and providing groundwork for future research. Despite the merit, some limitations should be noted before concluding. First of all, examination is of secondary data sources such as case studies derived from various organizations' reports. The assumption is that these data sources provide a rather exact picture of what is true in the field nationwide. Most organizations, except for USAC, investigated in this paper are non-profit organizations and stand for educational improvement. However, one limitation which this methodology might have is the possibility of the organizations' highlighting only the one direction that they want to claim. Their intentions behind the pub- 
lished reports are guesses, and the inferences superficially hypothesized, rather than genuinely investigated. Thus, the reliability is not surely proven. Notwithstanding this ambiguity, the analysis from the data can be reaffirmed through interviews and observations. Member checking can make this paper's interpretation more reliable.

Second, the amount of data is too small to produce a substantive result. Six interviews is a very limited number. Making convincing arguments, based on this small data set, is uncertain. Thus, more subjects and data need to be considered for future research. Another limitation is that all interviewees come from the same organization. They are all professors and have limited field experience, except for two professors from the education department. Although they have expertise in this kind of policy, their viewpoints could be subjective or oriented in some direction based on their experiences. What they said was not verified with practitioners, such as teachers, superintendents and other administrators in the field.

Lastly, while conducting this research, many new facts appeared regarding the subject matter; these could be further investigated. For instance, even though many funding schemes for educational technology exist, this paper could not address the relationship between E-Rate and other technology-related funding sources. This can be a subject for future research.

\section{Conclusion}

This paper inquired into the impact of E-Rate on social equity and educational efficacy in American public schools, based on the original purpose of the federal government's investment. Answering the research questions involved a document analysis and interviews. A total of seven documents that conducted case studies nationwide and six interviews were analyzed. As mentioned earlier, these documents provided many substantial cases from observations of elementary and secondary schools. Interviews also offered an opportunity for member checking of findings.

The findings are: For the questions about the effect of E-Rate on equity, a rather great improvement was made, but it just provided access to technology which is not enough for resolving the digital divide in schools. Even though the schools in poorer, rural, and underserved areas could have more Internet access points, complex application processes have prevented poorer schools, which have insufficient financial and human resources, from applying for a fair amount of available funds on a timely basis. This often results in disproportionate funding nationwide and increased the digital divide in the beginning of the program. Thus, the conclusion is that the digital divide persists between rich and poor schools, urban and rural schools, and even high schools and elementary schools.

For the questions about the effective incorporation of information technology into teaching and learning processes, startling gaps remain between the promise and reality of technology. Having technology does not necessarily mean effective use. Computers are very often left underused in the classroom. According to one survey conducted in 2003, only $80 \%$ of the computers are used each day. Some schools try to combine technologies with their curricula, and sometimes succeed. However, lack of tech-savvy teachers and lack of technical support have made many schools neglect technology for the integration with educational purposes. When teachers have no time for developing curricula and no help from technicians, they simply lay technology aside.

Conclusively, E-Rate could not bring efficacy to the education sector except for providing less than seamless Internet connection to schools. As Hudson (1994) indicated, before the legislation of the E-Rate program, the approach for universal service should extend to consider the potential benefits of access to education and social services beyond simple network connection and pricing. Therefore, the education sector should work together with the telecom sector and other private funding agencies at federal, state and local levels to ensure that the investment in schools is util- 
ized effectively. This investment from E-Rate is after all not about the cost of bringing Internet connection to schools but about investment in the future of the nation.

\section{References}

Bertot, J. C. (2000). Universal service in the networked environment: the education rate (E-Rate) debate. The Journal of Academic Librarianship, 26(1), 45-48.

Bracey, B. (2004, Jun. 17). E-Rate, technology and the national information infrastructure. Retrieved Jan. 15, 2005, from Benton Foundation ListServe, http://www.benton.org

Callison. D. (2004, Feb. 1). Digital divide: School library media activities. Education Module, 51, $37-$ 40. Retrieved Feb. 2, 2005, from ProQuest Database.

Center for Children and Technology (CCT). (2001). E-Rate student evaluation toolkit: A work-in-progress. Retrieved Feb. 1, 2005, from http://www2.edc.org/CCT/admin/publications/classroom/erate toolkit_2001.pdf

CEO Forum on Education and Technology. (2001, June). The CEO Forum school technology and readiness report: Key building blocks for student achievement in the 21st century. Retrieved April 16, 2005, from http://www.ceoforum.org/downloads/report4.pdf

Consortium for School Networking (CoSN). (2004). Digital leadership divide. Retrieved Feb. 2, 2005, from http://www.cosn.org/resources/grunwald/digital_leadership_divide.pdf

Cuban, L. (2001). Oversold and underused: Computers in the classroom. Cambridge, MA: Harvard University Press.

Dickard, N. (Ed.). (2002). Great expectations: Leveraging America's investment in educational technology. Washington, DC: Benton Foundation. Retrieved Feb. 1, 2005, from http://www2.edc.org/CCT/admin/publications/report/erate_greatexpect_2002.pdf

Dickard, N. (Ed.). (2003). The sustainability challenge: Taking edtech to the next level. Washington, DC: Benton Foundation. Retrieved Feb. 2, 2005, from http://www.benton.org/publibrary/sustainability/sus_challenge.html

Education and Library Networks Coalition [EdLiNC]. (2003). E-Rate: A vision of opportunity and innovation. Retrieved Jan., 17, 2003, from http://www.EdLiNC.org/pdf/ErateReport070803.pdf

Federal Communications Commission (FCC). (2004, Nov. 29). In the matter of federal-state joint board on universal service. Order on Reconsideration, FCC 04-237. Retrieved March 3, 2005, from http://www.fcc.gov/

Flamm, K. (2004). The role of economic, demographic, and state policy in broadband competition: An exploratory study. Presented at the annual convention of Telecommunications Policy Research Conference, Arlington, VA. October 2, 2004.

Gersick, A., Kim, C., Keane, J. T., Friedman, W., \& Culp, K. (2002). Assessments of students' technologybased work: An overview of the toolkit and case studies. In N. Dickard (Ed.), Great expectations: Leveraging America's investment in educational technology (pp.29-40). Washington, DC: Benton Foundation.

Goolsbee, A., \& Guryan, J. (2002). The impact of internet subsidies in public school. Working paper no. 9090, Cambridge, MA: National Bureau of Economic Research.

Guthrie, J. (2003, March 18). Computers idle in public schools. USA Today, p. 15A.

Honey, M. (2002). New approaches to assessing students' technology-based work. In N. Dickard (Ed.), Great expectations: Leveraging America's investment in educational technology. (pp. 24-28). Washington, DC: Benton Foundation.

Hudson, H. E. (2004) Universal access: What have we learned from E-Rate? Telecommunications Policy, $28,309-321$. 
Jayakar, K. P. (2004). Reforming E-Rate. Info, 6(1), 37-51.

Jung, J. Y., Qiu, J. L., \& Kim, Y. C. (2001). Internet connectedness and inequality: Beyond the "divide." Communication Research, 28(4), 507-535.

Macias, J. (2001). Connecting California's children: Is E-Rate enough? Latino Issues Forum. Retrieved Feb. 1, 2005, from http://www.lif.org/download/e rate.pdf

Murray, C. (2005, August 23). Dispute highlights eRate's ambiguities. eSchool News. Retrieved September 25, 2005, from http://www.eschoolnews.com/news/showStory.cfm?ArticleID=5831

National School Boards Foundation (NSBF). (2002). Are we there yet? Retrieved March 12, 2005, from http://www.nsbf.org/thereyet/fulltext.htm

Noll, R. G., Older-Aguilar, D., Rosston, G., \& Ross, R. R. (2000). The digital divide: Definitions, measurements, and policy issues. Retrieved June 5, 2005, from http://smealsearch.psu.edu/cache/papers/Business/280/http:zSzzSzgsbwww.uchicago.eduzSzfaczSzaus tan.goolsbeezSzteachingzSzdigdiv.pdf/the-digital-divide-definitions.pdf

Schools and Libraries Division (n.d). Program overview. Retrieved Feb. 23, 2005, from http://www.sl.universalservice.org/reference/

Schools and Libraries Division (SLD). (2005, April 18). SLD provides demand estimate for funding year 2005 to FCC. Retrieved April 19, 2005, from http://www.sl.universalservice.org/whatsnew/2005/042005.asp\#041805

Schuler, J. A. (1999). A critique of universal service, E-Rate and the chimera of the public's interest. Government Information Quarterly, 16(4), 359-369.

Shiver, J. (2003, Apr. 21). FCC plans stricter rules on ‘E-Rate' Net-access program. Los Angeles Times. Retrieved Jan. 18, 2005, from http://www.siliconvalley.com/mld/siliconvalley/5680997.htm?template=contentModules/printstory.jsp

Staihr, B., \& Sheaff, K. (2001). The success of the E-Rate in rural America. The Center for the Study of Rural America at the Federal Reserve Bank of Kansas City. Retrieved Feb. 3, 2005 from http://eric.ed.gov/ERICDocs/data/ericdocs2sql/content storage 01/0000019b/80/17/2f/49.pdf

Thierer, A., Crews, C. W. Jr., \& Pearson, T. (2002). Birth of the digital new deal: An inventory of high-tech pork barrel spending. Policy Analysis No.457, Washington, DC.: Cato Institute.

Trotter, A. (2000) Rating E-Rate. Education Week, 20(3), 3-6. Retrieved March 16, 2005 from http://www.edweek.org/

United States Government Accountability Office (US-GAO). (2005a). Telecommunications: greater involvement needed by FCC in the management and oversight of the E-Rate program. GAO-05-151. A report to the Chairman, Committee on Energy and Commerce, House of Representatives (Feb. 2005). Retrieved September 20, 2005, from http://www.gao.gov/new.items/d05151.pdf

United States Government Accountability Office (US-GAO). (2005b). Telecommunications: application of the anti-deficiency Act and other fiscal controls to FCC's the E-Rate program. GAO-05-546T (April 11, 2005). Retrieved September 20, 2005, from http://www.gao.gov/new.items/d05546t.pdf

Whelan, D. L. (2004, Nov. 1). E-Rate funding still up in the air; schools, libraries are left in the dark about discounted funds for Internet service. School Library Journal, pg.16.

White House. (2003). No child left behind. Retrieved March 30, 2005, from http://www.whitehouse.gov/news/reports/no-child-left-behind.html 


\section{Appendix: \\ Interview Questions (Estimated Time: 45 minutes)}

Basic Information (by email or previous information)

Name, Title, Age/Gender, Department, Major interest, Academic Career (Years)

The level of commitment to the subject matter of education and technology

\section{Equity Aspect}

1. The impact of the E-rate program on digital divide

2. Problems in terms of ensuring equity

3. Problems with the funding scheme of E-rate in terms of, e.g. amount and distribution

- Application process

- Funding coverage

- Distribution principles

- Budget shortage

- Funding mechanism

- Neglect of current conditions in schools

- Administrative problem

4. How to better ensure equity?

- Open-mindedness: commitment should be made to using telecommunication for development and absorbing the Internet into schools.

- Mentoring

- Carriers

- Other suggestions

\section{Efficacy Aspect}

1. How has information technology been positively used in teaching and learning?

2. Problems with actual use of technology

- Underused technology

- No improvement in students' performance

3. Reasons for the problems

- Poor quality of teachers

- Lack of confidence in technology

- Misguiding purpose of E-rate

- Inadequate support for technology

- Students' skills

4. How to improve the efficacy

- Objectives of E-rate

- Leadership adjustment

- Professional training initiatives

- Parents support

5. How to measure the integration 


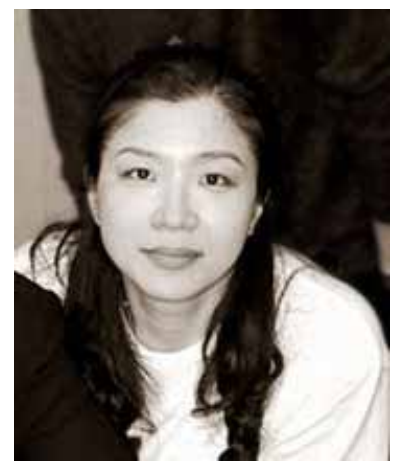

Euna Park (Mickey) is a doctoral candidate in the College of Communications at Pennsylvania State University. Before studying in the U.S., she was a researcher for a governmental institute, KISDI, in South Korea and published many analytical reports for Korea's government and industry. Her interest is in policy and economic aspects of mass media and telecommunications. She has presented papers at conferences, such as International Communication Association, Association for Education in Journalism and Mass Communication, and National Communication Association.

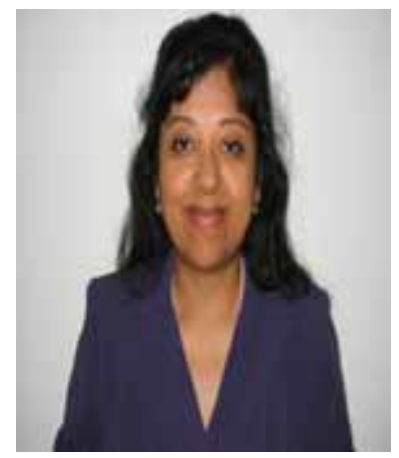

Hansa Sinha is a doctoral candidate in the College of Information Science and Technology at Pennsylvania State University. She holds a Master degree in Business Administration majoring in MIS from the same university. She also has a post-graduate diploma in Personnel Management from XLRI, India, and an undergraduate degree with majors in Economics and Education. She has served as application/programmer analyst, database administrator and webmaster in different departments at PSU. She has also worked as a substitute teacher in Connecticut.

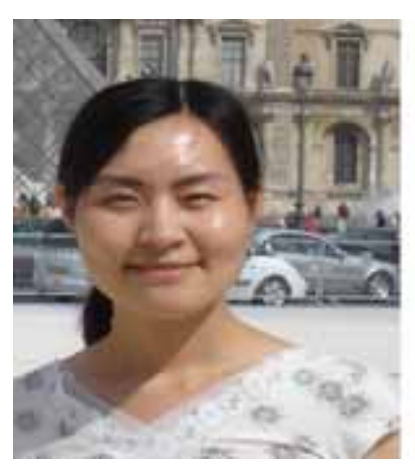

Jing Chong is a doctoral candidate in the College of Information Sciences and Technology at Pennsylvania State University. Her Bachelor's and Master's are in Library and Information Science. Her research interests include health inequality, health education on the web, digital divide and HIV/AIDS related social-technical issues. 